\title{
Inhibitory and Bactericidal Potential of Some Indigenous Functional Food-Plants Used in the O.R. Tambo District Municipality of South Africa
}

\author{
Collise Njume ${ }^{1,2 *}$, Bomkazi M. Gqaza3 ${ }^{3}$, Grace George ${ }^{3}$, Nomalungelo I. Goduka1 \\ ${ }^{1}$ Centre for Rural Development, Enkululekweni, Walter Sisulu University, Mthatha 5117, South Africa \\ ${ }^{2}$ Department of Medical Microbiology, Walter Sisulu University, Mthatha 5117, South Africa \\ ${ }^{3}$ Department of Medical Biochemistry, Walter Sisulu University, Mthatha 5117, South Africa \\ Email: ${ }^{*}$ cnjume@wsu.ac.za; ${ }^{*}$ njumecol@yahoo.com
}

Received June 2014

\section{Abstract}

Antimicrobial resistance is a major problem in the management of infectious diseases. African indigenous functional food-plants such as Chenopodium album and Solanum nigrum may constitute important sources of phytochemical constituents for the synthesis of antimicrobial compounds against infectious organisms. The objective of this study was to determine the antimicrobial properties of Chenopodium album and Solanum nigrum-leaves used as functional food-plants in the O.R. Tambo district municipality of South Africa. Organic and aqueous solvent-extracts of $C$. album and S. nigrum were tested against Staphylococcus aureus (ATCC 29213), Pseudomonas aeruginosa (ATCC127853), Bacillus subtilis (ATCC 6051), Escherichia coli (25922) and Enterococcus faecalis (51299) using standard microbiological techniques. Ciprofloxacin was included in all the experimental runs as positive control antibiotic. The aqueous extracts of both plants were the most active with zones of inhibition diameters ranging from $0 \mathrm{~mm}-20 \mathrm{~mm}$ and minimum inhibitory concentration $\left(\mathrm{MIC}_{50}\right.$ ) values ranging from $0.63 \mathrm{mg} / \mathrm{mL}-10 \mathrm{mg} / \mathrm{mL}$. The positive control antibiotic was highly active with zones of inhibition diameters ranging from $17 \mathrm{~mm}-31 \mathrm{~mm}$ and $\mathrm{MIC}_{50}$ values from $0.0003 \mathrm{mg} / \mathrm{mL}-0.0005 \mathrm{mg} / \mathrm{mL}$ for all the bacteria tested. Both extracts were bactericidal with minimum bactericidal concentration (MBC) ranges from $2.5 \mathrm{mg} / \mathrm{mL}-20 \mathrm{mg} / \mathrm{mL}$. From the results, it can be concluded that both plants possess compounds with antimicrobial properties, thus validating scientifically their use in traditional medicine. However, more studies to document the respective plant-principles responsible for antimicrobial activity of these plants would shed more light on their functional properties.

\section{Keywords}

Antimicrobial Resistance, Sensitivity Tests, Indigenous Leafy Vegetables, Eastern Cape Province, South Africa

\footnotetext{
${ }^{*}$ Corresponding author.

How to cite this paper: Njume, C., Gqaza, B.M., George, G. and Goduka, N.I. (2014) Inhibitory and Bactericidal Potential of Some Indigenous Functional Food-Plants Used in the O.R. Tambo District Municipality of South Africa. Journal of Biosciences and Medicines, 2, 34-40. http://dx.doi.org/10.4236/jbm.2014.26006
} 


\section{Introduction}

Bacterial antimicrobial resistance against commonly used antibiotics is distressingly on the rise [1]. Patients infected with resistant organisms are more likely to have longer more expensive hospital stays [2]. The modification of chemotherapeutic agents to limit this problem has been greatly successful. However, many reports also indicate that many of the drugs are being rendered obsolete by microbial drug-resistance [3]. As a result, the treatment of microbial infection is becoming increasingly complicated. Physicians have now resorted to the use of combination therapy, increasing the cost of treatment even more. Reports on Escherichia coli, Pseudomonas aeruginosa, Staphylococcus aureus, Bacillus subtilis and Enterococcus faecalis infections and antibacterial resistance reveal the need for a constant search of new drugs against these organisms [4] [5]. E. coli is a major cause of travellers' diarrhoea, one of the most common forms of diarrhoea worldwide [6] [7]. Both E. coli and $P$. aeruginosa are also major causes of urinary tract infections while $S$. aureus and $E$. faecalis are common causes of nosocomial infections [8] [9]. B. subtilis infections are not common but few cases have been reported in the literature in patients with oesophageal perforations [10]. The use of medicinal plants in the treatment of human infections is a common practice in many remote areas of Africa with inadequate health care facilities. Chenopodium album and Solanum nigrum are functional food-plants with wide nutritional and medicinal importance among rural communities in the O.R. Tambo District Municipality of South Africa [11]. They are jointly referred to as imifino ezikhulelayo in isiXhosa, meaning indigenous vegetable. C. album is locally known as imbikicane while S. nigrum is known as umsobo [12] [13]. Both plants grow wildly in bushes, barren land and roadside paths from where they are harvested either for nutritional or medicinal purposes. In some parts of India, $C$. album is also used in ayurveda for treating anorexia, cough, dysentery, diarrhoea, oedema, piles and worm infestations [14]. Despite their medicinal uses, very little information is available in the literature about their pharmacological potential. This is surprising considering the ever-increasing rate of antimicrobial resistance of human infectious organisms against currently used drugs. The aim of this study therefore was to investigate the antimicrobial properties of these plants in an attempt to identify cheap sources of compounds for the synthesis of new drugs against medically important bacteria.

\section{Materials and Methods}

\subsection{Bacterial Strains}

Standard bacterial strains including Pseudomonas aeruginosa ATCC 127853, Escherichia coli ATCC 25922, Staphylococcus aureus ATCC 29213, Enterococcus faecalis ATCC 51299 and Bacillus subtilis ATCC 6051 (American Type Culture Collection, Rockville, MD) obtained from the stock culture of the National Health Laboratory Services (NHLS), Nelson Mandela Academic Hospital, Mthatha were used in this study. Ethical clearance was obtained from the Eastern Cape Department of Health and the Ethics Committee of the Faculty of Health Sciences, Walter Sisulu University (WSU). The organisms were cultured on nutrient agar (Oxoid Llt., Basingstoke, UK).

\subsection{Collection and Preparation of Plant Material}

The leaves of C. album and S. nigrum were harvested from home gardens and along bush paths in the vicinity of WSU main campus in Mthatha in October 2012. The plants were identified by Dr. Kathleen Immelman of the Department of Botany at WSU and voucher specimens were prepared and deposited in the Kei herbarium (CN01 and CN02). The plant leaves were washed with tap water to remove dirt and soil particles. The plant leaves were placed on cardboards and dried at $50{ }^{\circ} \mathrm{C}$ for 24 hours in a hot air oven (Heraeus, Schutzart). The plant material was powdered (ATO Mix, Cambridge) and stored in airtight containers at $5{ }^{\circ} \mathrm{C}$ for further analysis.

\subsection{Preparation of Plant Extracts}

Approximately $400 \mathrm{~g}$ of dried powdered plant material was exhaustively extracted in different solvents. The plant material was separately soaked in $700 \mathrm{~mL}$ of concentrated hexane, acetone, ethanol, methanol and water in 2L volumetric flasks (Schott, Durban). The flasks were placed in an orbital shaker incubator (labcon, Maraisburg) for $48 \mathrm{~h}$ [15]. The plant material was centrifuged at $1006.2 \mathrm{x}$ g for 5 minutes and filtered through a fritted 
filter funnel of pore size $60 \AA$. The procedure was repeated twice and the three extracts combined and concentrated to dryness under vacuum (Büchi, Switzerland). The dried crude extract was collected in porcelain evaporating dish (Haldenwanger, Berlin) and left open in a biosafety class 2 cabinet (Durban, South Africa) for complete evaporation of residual solvents. The aqueous extracts were lyophilized [16]. A 2-g sample of each extract was used for the preliminary bioassay, and where possible, another $2 \mathrm{~g}$ or more was put in universal bottles and kept in the extract bank. Stock solutions were prepared by dissolving the extracts in $80 \%$ acetone (a concentration we found to be non inhibitory to any of the bacterial strains tested).

\subsection{Screening of Crude Extracts for Antibacterial Activity}

The agar-well diffusion method was used for this analysis [17]. Briefly, each bacterial suspension prepared in 0.9\% saline (McFarland turbidity standard 0.5 ) was inoculated by spreading on Mueller Hinton agar (Oxoid Llt., Basingstoke, UK) plates and allowed to dry for 15 minutes. Wells (6mm in diameter) were punched into the agar using a sterile stainless steel borer and filled with $70 \mu \mathrm{L}$ of the extract at $100 \mathrm{mg} / \mathrm{mL}$. Seventy microliters of $0.005 \mathrm{mg} / \mathrm{mL}$ ciprofloxacin and $80 \%$ acetone were included in all experiments as positive and negative controls, respectively. The plates were incubated at $37^{\circ} \mathrm{C}$ for 24 hours, after which the diameters of zones of inhibition were measured in millimetres. The experiment was repeated twice, and means for zones were recorded.

\subsection{Determination of Minimum Inhibitory Concentration (50\% Susceptibility)}

Based on their good antimicrobial activity in the screening, the aqueous extracts were selected for determination of minimum inhibitory concentration $\left(\mathrm{MIC}_{50}\right.$ ) using the micro broth dilution technique performed in 96-well plates [18]. Two-fold dilutions of the extract and control antibiotic (Ciprofloxacin) were prepared in the wells containing Mueller Hinton broth. The final extract concentration ranged from $20-0.31 \mathrm{mg} / \mathrm{mL}$ while that of the control antibiotic ranged from $0.005-0.00015 \mathrm{mg} / \mathrm{mL}$. Exactly $20 \mu \mathrm{L}$ of an 18-hour old broth culture (McFarland turbidity standard 0.5 ) of the bacteria was inoculated into $180 \mu \mathrm{L}$ of extract-containing culture medium. Negative control wells were prepared with culture medium only and bacteria suspension and broth only respectively. An automatic ELISA micro plate reader (Tokyo, Japan) adjusted to $590 \mathrm{~nm}$ was used to measure the absorbance of the plates before and after 24-hour incubation. The absorbencies were compared to detect an increase or decrease in bacterial growth and the values plotted against concentration. The lowest concentration of the test extract resulting in inhibition of $50 \%$ of bacterial growth was recorded as the MIC.

\subsection{Determination of Minimum Bactericidal Concentration (MBC)}

The MBC was determined following well established procedures [19]. Briefly, the entire content of the MIC well $(\approx 200 \mu \mathrm{L})$ was serially tenfold diluted in $0.9 \%$ saline. A loop-full was taken from each tube and inoculated into Mueller Hinton agar plates and incubated for $24 \mathrm{~h}$ at $37^{\circ} \mathrm{C}$. The $\mathrm{MBC}$ was recorded as the lowest concentration of the extract or antibiotic that gave complete inhibition of colony formation of the test bacteria at the later cultivation.

\subsection{Statistical Analysis}

The statistical package used for analysis was SPSS v18.0 (SPSS Inc., Chicago, IL). One-way analysis of variance (ANOVA) was used to compare the mean difference in inhibitory activities of extracts and control antibiotic, followed by Turkey's post-hoc test. Differences were considered significant at $P<0.05$.

\section{Results}

The zones of inhibition diameters of active plant extracts ranged from $0 \mathrm{~mm}-20 \mathrm{~mm}$ while those for the control antibiotic ranged from $17 \mathrm{~mm}-31 \mathrm{~mm}$. Hexane extracts of C. album and methanol extracts of both plants were inactive (Table 1).

\subsection{Minimum Inhibitory Concentration of Active Crude Extracts and Control Antibiotic}

Based on agar-well results, the most active extracts (aqueous) were selected for MIC and MBC determination alongside the positive control antibiotic. The activity of the aqueous extracts was confirmed with $\mathrm{MIC}_{50}$ values 
Table 1. Antimicrobial activity of crude extracts of S. nigrum and C. album as revealed by the agar-well diffusion technique.

\begin{tabular}{|c|c|c|c|c|c|c|c|c|c|c|c|}
\hline \multicolumn{6}{|c|}{ S. nigrum } & \multicolumn{6}{|c|}{ C. album } \\
\hline & $\mathbf{H}$ & A & $\mathbf{E}$ & $\mathbf{M}$ & $\mathbf{W}$ & $\mathbf{H}$ & A & $\mathbf{E}$ & $\mathbf{M}$ & $\mathbf{W}$ & CIP \\
\hline \multicolumn{12}{|l|}{ Bact } \\
\hline \multirow[t]{3}{*}{ Bs } & 15 & 0 & 10 & 0 & 17 & 0 & 13 & 0 & 0 & 14 & 22 \\
\hline & 11 & 10 & 10 & 0 & 20 & 0 & 21 & 0 & 0 & 17 & 29 \\
\hline & 10 & 0 & 12 & 0 & 15 & 0 & 11 & 0 & 0 & 17 & 31 \\
\hline \multirow[t]{3}{*}{ Sa } & 0 & 0 & 10 & 0 & 10 & 0 & 0 & 0 & 0 & 11 & 19 \\
\hline & 7 & 0 & 10 & 0 & 12 & 0 & 0 & 0 & 0 & 10 & 19 \\
\hline & 9 & 0 & 9 & 0 & 14 & 0 & 10 & 9 & 0 & 10 & 17 \\
\hline \multirow[t]{3}{*}{ Ef } & 0 & 0 & 11 & 0 & 0 & 0 & 0 & 0 & 0 & 17 & 21 \\
\hline & 0 & 0 & 15 & 0 & 0 & 0 & 0 & 0 & 0 & 14 & 19 \\
\hline & 0 & 0 & 11 & 0 & 0 & 0 & 11 & 0 & 0 & 14 & 21 \\
\hline \multirow[t]{3}{*}{ Ec } & 9 & 0 & 9 & 0 & 11 & 0 & 10 & 9 & 0 & 9 & 21 \\
\hline & 0 & 0 & 10 & 0 & 10 & 0 & 0 & 0 & 0 & 10 & 18 \\
\hline & 0 & 11 & 13 & 0 & 10 & 0 & 10 & 0 & 0 & 9 & 18 \\
\hline \multirow[t]{3}{*}{$\mathbf{P a}$} & 0 & 0 & 10 & 0 & 13 & 0 & 0 & 0 & 0 & 15 & 19 \\
\hline & 0 & 0 & 13 & 0 & 12 & 0 & 0 & 10 & 0 & 17 & 27 \\
\hline & 0 & 0 & 9 & 0 & 10 & 0 & 0 & 0 & 0 & 16 & 23 \\
\hline Mean \pm SD & $4.1 \pm 5.4$ & $1.4 \pm 3.6$ & $10.8 \pm 1.7$ & 0 & $10.3 \pm 6.0$ & $\mathbf{0}$ & $5.7 \pm 6.8$ & $1.8 \pm 3.8$ & 0 & $13.3 \pm 3.1$ & $21.6 \pm 4.2$ \\
\hline
\end{tabular}

Last row data are Mean \pm SD of 15 determinations for each plant crude extract; H: hexane; A: acetone; E: ethanol; M: methanol; W: water; Bact: bacteria; Bs: Bacillus subtilis; Sa: Staphylococcus aureus; Ef: Enterococcus faecalis; Ec: Escherichia coli; Pa: Pseudomonas aeruginosa.

of $0.63 \mathrm{mg} / \mathrm{mL}-10 \mathrm{mg} / \mathrm{mL}$ and $0.63 \mathrm{mg} / \mathrm{mL}-7.5 \mathrm{mg} / \mathrm{mL}$ for S. nigrum and C. album respectively (Figure 1).

\subsection{Minimum Bactericidal Concentration of Active Crude Extracts and Control Antibiotic}

Aqueous crude extracts of both plants were also bactericidal against the tested bacteria with MBC values ranging from $2.5 \mathrm{mg} / \mathrm{mL}$ and $5.0 \mathrm{mg} / \mathrm{mL}-20 \mathrm{mg} / \mathrm{mL}$ for C. album and S. nigrum respectively (Figure 2). MIC and MBC values of $0.0003 \mathrm{mg} / \mathrm{mL}$ and $0.001 \mathrm{mg} / \mathrm{mL}$ respectively were recorded for the control antibiotic and were the least values in the entire study (Figure $1 \&$ Figure 2).

\section{Discussion}

Medicinal plants may constitute an important source of therapeutic compounds against human infectious organisms. Many plants have been reported to contain flavonoids, alkaloids, tannins, phenols, saponins or other secondary metabolites which serve as defence mechanisms against micro organisms, insects and animals [20]. These compounds are known to act in different ways to exert antimicrobial action. The results of this study indicate that crude extracts of $C$. album and $S$. nigrum have the potential for further evaluation in the search for antibacterial compounds. Gram-positive organisms; S. aureus, E. faecalis and B. subtilis were the most susceptible in the entire study while Gram-negatives; $E$. coli and P. aeruginosa were less susceptible (Table 1, Figure 1 \& Figure 2). The difference in susceptibility between Gram-negative and Gram-positive bacteria to antimicrobial agents has been reported by other researchers [20] [21] and may be attributed to structural differences in the cell wall of both organisms. Gram-negative bacteria have a lipid protective sheath around their cell walls which seems to shield them from the effects of antimicrobial agents [22]. All the bacteria tested were highly 


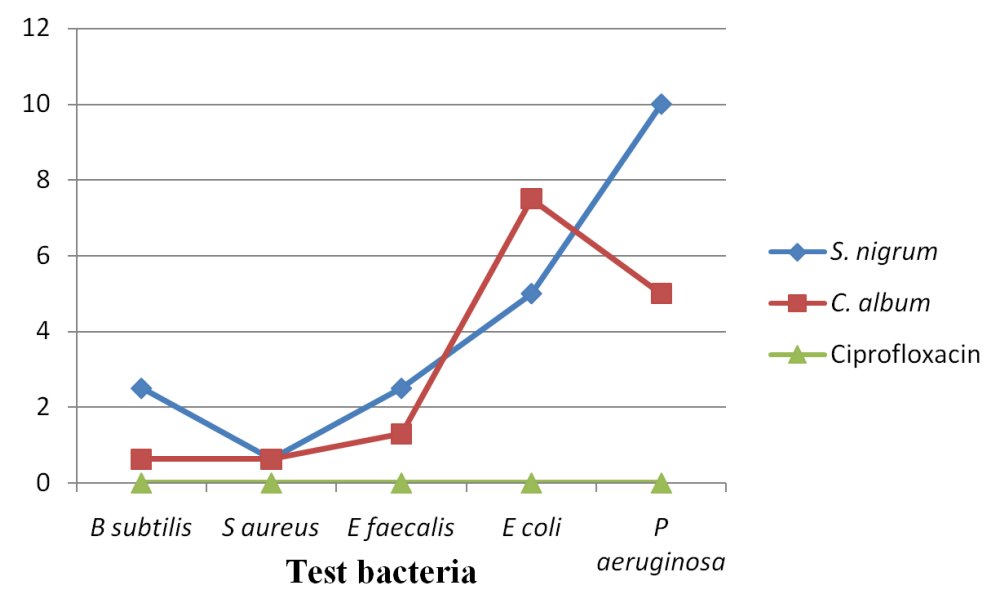

Figure 1. Minimum Inhibitory Concentration $(\mathrm{mg} / \mathrm{mL})$ values of plant crude extracts and control antibiotic tested against some bacteria of medical importance.

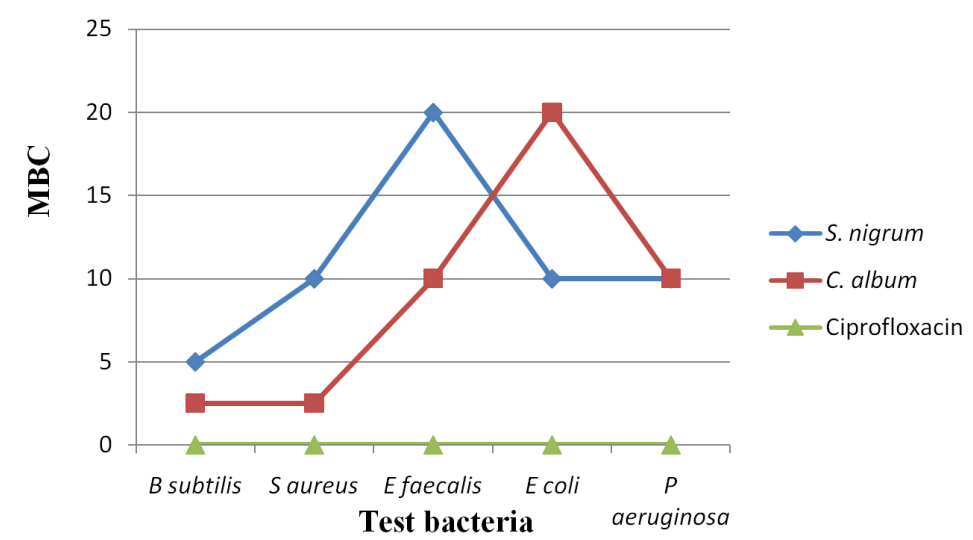

Figure 2. Minimum Bactericidal Concentration $(\mathrm{mg} / \mathrm{mL})$ values of plant crude extracts and control antibiotic tested against some bacteria of medical importance.

susceptible to Ciprofloxacin, the control antibiotic (Table 1, Figure $1 \&$ Figure 2). The plant crude extracts were relatively less active when compared to Ciprofloxacin $(P<0.05)$. This was expected as the control antibiotic is a purified compound with excipients to facilitate activity. The crude extracts on the other hand are made of numerous compounds; some of which may have antagonistic properties against each other. Equally important is the fact that the quantity of the active ingredient in the crude extracts may be in minute quantities, not enough to exhibit the type of activity demonstrated by the control antibiotic. Of all the bacteria tested, B. subtilis and $S$. aureus were most susceptible to aqueous extracts of the plants, producing large zones of inhibition diameters (Table 1), low MIC and MBC values (Figure $1 \&$ Figure 2). However, there were no significant differences in antibacterial activity between the aqueous extracts of C. album and S. nigrum $(P>0.05)$.

\section{Conclusion}

The current study illustrates the antibacterial properties of crude extracts of C. album and S. nigrum against some selected bacteria of medical importance. The study shows that aqueous extracts of both plants are inhibitory and bactericidal to $S$. aureus, B. subtilis, P. aeruginosa, E. coli and E. faecalis. These findings are consistent with their folkloric use in the treatment of stomach-related morbidities in the O.R. Tambo District Municipality of South Africa. However, more studies to document the plants active ingredients will shed more light on their pharmacological relevance as antibacterial agents. 


\section{Acknowledgements}

We are grateful to the Department of Science and Technology (DST) and the National Research Foundation (NRF), South Africa for funding this study through a grant awarded to the Research Chair for Indigenous Knowledge System at Walter Sisulu University, South Africa.

\section{References}

[1] Falagas, M.E., Karageorgopoulos, D.E., Leptidis, J. and Korbila, I.P. (2013) MRSA in Africa: Filing the Global Map of Antimicrobial Resistance. PLoS One, 8, e68024. http://dx.doi.org/10.1371/journal.pone.0068024

[2] Matsuura, G.T., Pharm, D. and Barg, N. (2013) Update on the Antimicrobial Management of Foot Infections in Patients with Diabetes. Clinical Diabetes, 31, 59-65. http://dx.doi.org/10.2337/diaclin.31.2.59

[3] Balsalobre, L.C., Dropa, M. and Matte, M.H. (2014) An Overview of Antimicrobial Resistance and Its Public Health Significance. Brazilian Journal of Microbiology, 45, 1-5. http://dx.doi.org/10.1590/S1517-83822014005000033

[4] Gupta, K., Hooton, T.M. and Stamm, W.E. (2001) Increasing Antimicrobial Resistance and the Management of Uncomplicated Community-Acquired Urinary Tract Infections. Annals of Internal Medicine, 135, 45-50. http://dx.doi.org/10.7326/0003-4819-135-1-200107030-00012

[5] Tamma, P.D., Cosgrove, S.E. and Maragakis, L.L. (2012) Combination Therapy for Treatment of Infections with Gram Negative Bacteria. Clinical Microbiology Reviews, 25, 450-470. http://dx.doi.org/10.1128/CMR.05041-11

[6] Mittal, R., Aggarwal, S., Sharma, S., Chhibber, S. and Harjai, K. (2009) Urinary Tract Infections Caused by Pseudomonas aeruginosa: A Minireview. Journal of Infection and Public Health, 2, 101-111. http://dx.doi.org/10.1016/j.jiph.2009.08.003

[7] Canizalez-Roman, A., Gonzalez-Nunez, E., Vidal. J.E., Flores-Villasenor, H. and Leon-Sicairos, N. (2013) Prevalence and Antibiotic Resistant Profiles of Diarrheagenic Escherichia coli Strains Isolated from Food Items in North Western Mexico. International Journal of Food Microbiology, 164, 36-45. http://dx.doi.org/10.1016/j.ijfoodmicro.2013.03.020

[8] Sood, S., Malhotra, M., Das, B.K. and Kapil, A. (2008) Enterococcal Infections and Antimicrobial Resistance. Indian Journal of Medical Research, 128, 111-121.

[9] Oli, A.K., Sungar, R., Shivshetty, N., Hosamani, R. and Rivansiddappa, K.C. (2012) A Study of Scanning Electron Microscopy of Vancomycin Resistant Enterococcus faecalis from Clinical Isolates. Advances in Microbiology, 2, 93-97. http://dx.doi.org/10.4236/aim.2012.22012

[10] Jeon, Y.L., Yang, J.J., Kim, M.J., Lim, G., Cho, S.Y., Park, T.S., Suh, J.T., Park, Y.H., Lee, M.S., Kim, S.C. and Lee, H.J. (2012) Combined Bacillus licheniformis and Bacillus subtilis Infection in a Patient with oesophageal Perforation. Journal of Medical Microbiology, 61, 1766-1769. http://dx.doi.org/10.1099/jmm.0.042275-0

[11] Njume, C., Goduka, N.I. and George G. (2014) Indigenous Leafy Vegetables (imifino, morogo, muhuro) in South Africa: A Rich and Unexplored Source of Nutrients and Antioxidants. African Journal of Biotechnology, 13, 1933-1942.

[12] Gqaza, B.M., Njume, C., Goduka, N.I. and George, G. (2013a) Nutritional Assessment of Chenopodium album L. (Imbikicane) Young Shoots and Mature Plant-Leaves Consumed in the Eastern Cape Province of South Africa. International Proceedings of Chemical, Biological and Environmental Engineering, 27-28 July, Moscow, Russia. 53, 97-102.

[13] Gqaza, M.B., Njume, C., Goduka, I.N. and Grace, G. (2013b) The Proximate Composition of S. nigrum Plant-Leaves Consumed in the Eastern Cape Province of South Africa. International Proceedings of Chemical, Biological and Environmental Engineering, 27-28 July, Moscow, Russia. 53, 103-106.

[14] Yadav, N., Vasudeva, N., Singh, S. and Sharma, S.K. (2007) Medicinal Properties of Genus Chenopodium Linn. Natural Product Radiance, 6, 131-134.

[15] Njume, C., Afolayan, A.J. and Ndip, R.N. (2011) Diversity of Plants Used in the Treatment of Helicobacter pylori-Associated Morbidities in the Nkonkobe Municipality of the Eastern Cape Province of South Africa. Journal of Medicinal Plants Research, 5, 3146-3151.

[16] Castillo-Juárez, I., González, V., Aime-Aguilar, H., Martínez, G., Linares, E., Bye, R. and Romero, I. (2009) AntiHelicobacter pylori Activity of Plants Used in Mexican Traditional Medicine for Gastrointestinal Disorders. Journal of Ethnopharmacology, 122, 402-405. http://dx.doi.org/10.1016/j.jep.2008.12.021

[17] Boyanova, L., Gergova, G., Nikolov, R., Derejian, S., Lazarova, E., Katsarov, N., Mitov, I. and Krastev, Z. (2005) Activity of Bulgarian Propolis against 94 Helicobacter pylori Strains in Vitro by Agar-Well Diffusion, Agar Dilution and Disc Diffusion Methods. Journal of Medical Microbiology, 54, 481-483. http://dx.doi.org/10.1099/jmm.0.45880-0

[18] Bonacorsi, C., Raddi, M.S.G., Iracilda, Z.C., Sannomiya, M. and Vilegas, W. (2009) Anti-Helicobacter pylori Activity and Immunostimulatory Effect of Extracts from Byrsonima crassa Nied. (Malpighiaceae). Complementary and Alternative Medicine, 9, 1472-6882. http://dx.doi.org/10.1186/1472-6882-9-2 
[19] Nethathe, B.B. and Ndip, R.N. (2011) Bioactivity of Hydnora africana on Selected Bacteria Pathogens: Preliminary Phytochemical Screening. African Journal of Microbiology Research, 5, 2820-2826.

[20] Madduluri, S., Rao, K.B. and Sitaram, B. (2013) In Vitro Evaluation of Antibacterial Activity of Five Indigenous Plants Extracts against Five Bacteria Pathogens of Humans. International Journal of Pharmacy and Pharmaceutical Sciences, 5, 679-684.

[21] Cock, I. (2007) Antibacterial Activity of Selected Australian Native Plant Extracts. The Internet Journal of Microbiology, 4, 76-81.

[22] Silhavy, T.J., Kahne, D. and Walker, S. (2010) The Bacterial Cell Envelope. Cold Spring Harbor Perspectives in Biology, 2, 1-17. http://dx.doi.org/10.1101/cshperspect.a000414 
Scientific Research Publishing (SCIRP) is one of the largest Open Access journal publishers. It is currently publishing more than 200 open access, online, peer-reviewed journals covering a wide range of academic disciplines. SCIRP serves the worldwide academic communities and contributes to the progress and application of science with its publication.

Other selected journals from SCIRP are listed as below. Submit your manuscript to us via either submit@scirp.org or Online Submission Portal.
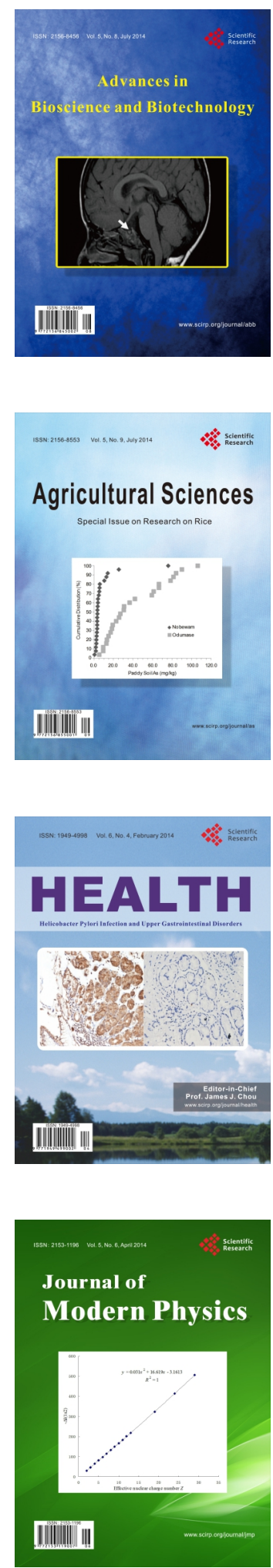
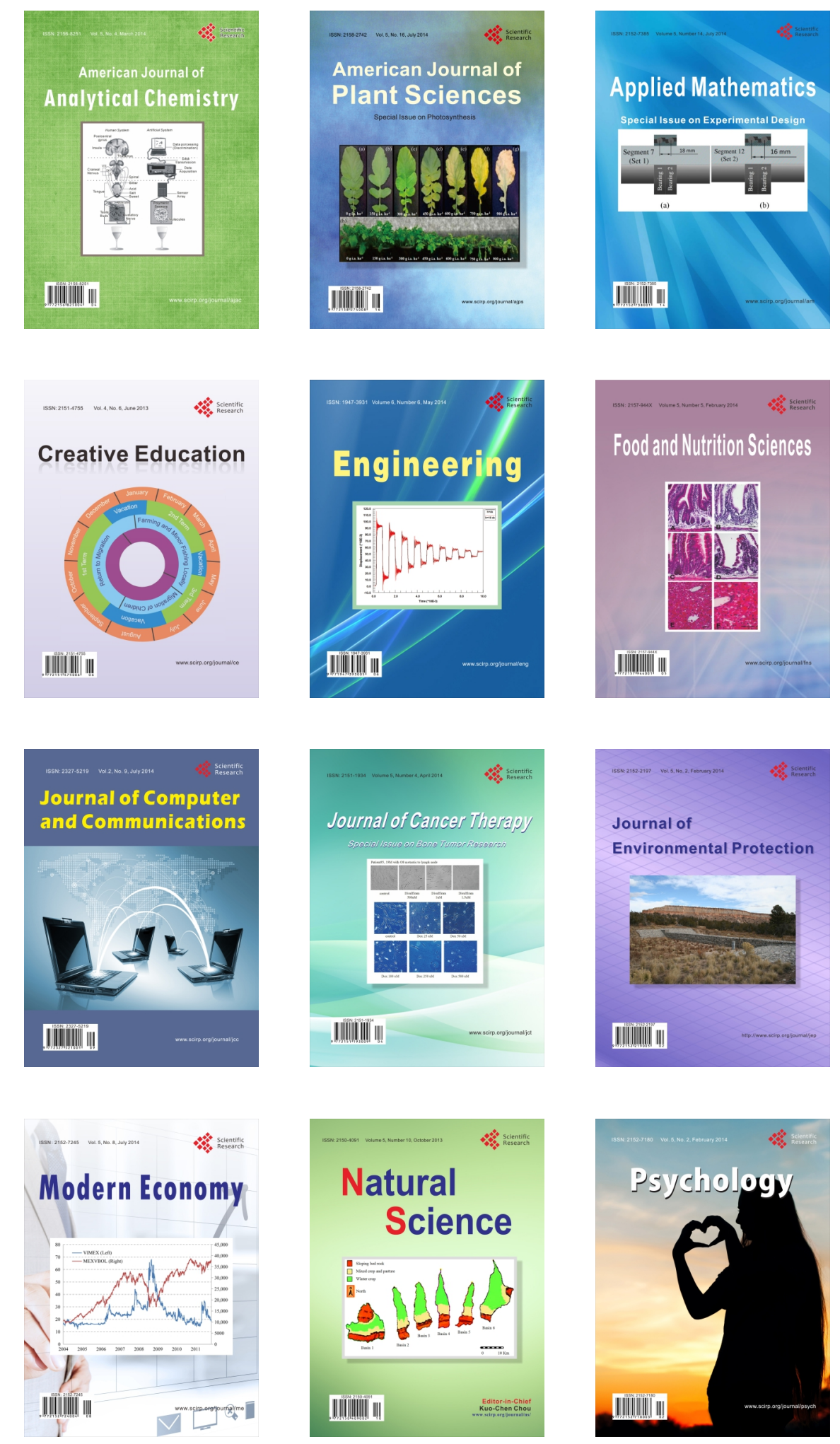